\title{
Comment
}

\section{Trabalho: Uma abordagem Social, Ontológica e Educacional}

Maria Lucineide Caetana Barbosa Sampaio ${ }^{l}$

Resumo: O presente artigo faz uma análise sobre o trabalho na nossa sociedade capitalista em sua concepção histórica, social, ontológica, político e econômico. Será analisado o conceito de trabalho como uma forma de desenvolvimento humano, ressaltando a sua importância para a existência da sociedade. Faz-se necessário discursar sobre o trabalho na sociedade capitalista, as relações da educação com o trabalho e formação profissional, principalmente sobre como pensar em educação como um caminho para a libertação alienatória do trabalho, instigando a população a pensar em educação como algo essencial para autonomia e desenvolvimento psicossocial e cultural, e não como uma solução direta para todos os problemas humanos, principalmente econômicos. Por fim, o discurso produzido neste artigo faz com que se compreenda o trabalho não apenas como algo mecânico, mas como um conjunto de esforços que se realiza para a construção de uma sociedade melhor e como um meio de realização pessoal, uma necessidade que deve ser mantida em toda e qualquer forma de sociedade.

Palavras-chave: Trabalho; Educação; Ontologia.

\section{Work: A Social, Ontological And Educational Approach}

\begin{abstract}
This article does an analysis on the work in our capitalist society in her conception historical, social, ontological, economic and political. will be analyzed the concept of work as a way to human development, emphasizing its importance for the existence of society. it is necessary to speak on labor in capitalist society, the relationship of education with work and training, especially on how to think of education as a way to release work, instigating the population thinking of education as something essential for autonomy and development psychosocial and cultural, and not as a solution direct for all human problems, especially economic. finally, the speech produced in this article makes if understand the work not only as something mechanical, but as a set of efforts that takes place to building a better society and as a means of fulfillment, a need to be kept in any form of society.
\end{abstract}

Keywords: work; education; ontology.

\footnotetext{
${ }^{1}$ Professora do ensino fundamental e médio, habilitada em Letras pelas Universidade Regional do Cariri (URCA) e especializada em Planejamento Educacional. Aluna regularmente matriculada no curso de Mestrado pela Anne Sullivan University. E-mail: lucineide-caetana@ hotmail.com.
} 
Id on Line Revista Multidisciplinar e de Psicologia

Id on Line Multidisciplinary and Psycology Journal

\section{Introdução}

Debater sobre a questão do trabalho exige entendê-lo nos seus mais variados sentidos, entendendo-se que ele está diretamente ligado ao sujeito, sociedade e educação. É o trabalho que produz o objeto, que transforma a matéria, que modela e torna realidade aquilo que antes era apenas um pensamento. Pode-se ver o trabalho, no sentido de que ele individualiza o sujeito tornando-o capaz de produzir algo. Ou, que ele existe como um meio de produção, capaz de sustentar o indivíduo e suprir as suas necessidades. Neste último caso, temos o sentido econômico que o trabalho passou a ter, a medida que progrediu a sociedade. Com o progresso vieram as fabricas, o trabalho mecânico, a venda e troca do trabalho braçal e a da mão de obra humana como uma mercadoria, dentre outras coisas. Num sentido social ele passou a ser o que divide a sociedade em classes. Uma proprietária dos meios de produção e outra que vende a sua força de trabalho. Em seu sentido ontológico, ele é o que diferencia o homem de outros animais, sendo o homem o único animal na natureza, capaz de realizar um trabalho de forma consciente, e não apenas instintivo.

Atualmente, vive-se uma crise do trabalho e capitalismo. Mesmo em muitas sociedades a educação sendo um direito constitucional, que deve ser garantido pelo Estado, ainda é crescente o número de pessoas escolarizadas que estão em situação de desemprego, ou que trabalham mas de forma informal, sem obter direitos trabalhistas.

É necessário pensar como o capitalismo transforma a sociedade, bem como em aspectos positivos e negativos, em como ele transformou o sentido ontológico do trabalho e, principalmente, como a educação pode ser uma saída para a alienação e para os problemas sociais, ou até mesmo se o problema real consiste em querer que a educação tenha total responsabilidade de ser a resposta para solucionar todos esses problemas que acomete a sociedade contemporânea. 
Id on Line Revista Multidisciplinar e de Psicologia

Id on Line Multidisciplinary and Psycology Journal

\title{
O trabalho, conceito e sociedade
}

O homem na natureza é a única espécie que tem consciência de si e do mundo, que é capaz de agir por vontade própria, de questionar, pensar racionalmente e enunciar-se, porém, ele também se diferencia do animal irracional por outro atributo, o de ser capaz de transformar a matéria, agindo sobre ela com o trabalho de transformá-la em algo que atenda a sua necessidade. "O trabalho, portanto, é um processo entre o homem e a natureza, um processo em que o homem, por sua própria ação, media, regula e controla seu metabolismo com a natureza" (NETTO; BRAZ, p. 31, 2006). O animal tem as suas funções na natureza realizando trabalhos cotidianos para manter o equilíbrio, mas o homem é capaz de criar, de modelar a matéria para atingir objetivos próprios, seus idealismos.

Desta forma Marx nos faz compreender que quando:

\begin{abstract}
Uma aranha executa operações semelhantes às do tecelão e a abelha envergonha mais de um arquiteto humano com a construção dos favos de suas colmeias. Mas o que distingue, de antemão, o pior arquiteto da melhor abelha é que ele construiu o favo em sua cabeça, antes de construí-lo em cera. No fim do processo de trabalho obtém-se um resultado que já no início deste existiu na imaginação do trabalhador, e, portanto, idealmente. Ele não apenas efetua uma transformação da forma da matéria natural; realiza, ao mesmo tempo, na matéria natural, o seu objetivo. (MARX, apud, NETTO; BRAZ, p. 31, 2006).
\end{abstract}

O conceito de trabalho pode ser definido como várias atividades produzidas ou realizadas por indivíduos que desejam alcançar com esse conjunto de atividades um objetivo. Desta forma para que exista sociedade e progresso é necessário que exista trabalho, a inercia não é capaz de criar nada, uma ideia não pode ser desenvolvida ou executada se ela não for trabalhada entendendo que não se trata apenas do braçal, mas todo esforço e atividade que fazemos para realizar tal objetivo.

O trabalho torna-se fundamental para o homem à medida que ele vai evoluindo como indivíduo e sociedade, é através dele que o homem compreende o seu lugar na natureza, que ele aprende a conviver em sociedade e respeitar o espaço do outro, a compartilhar e auxiliar o outro, "ele possibilita o desenvolvimento das capacidades humanas, das forças produtivas, das relações sociais, de modo que a sociedade se torne cada vez mais desenvolvida e complexa" (LESSA, 1999, p. 25-26). 
Humanizar o sujeito faz parte do processo social que está associado ao trabalho, em seu sentido social ele possibilita diversas formas de interação humana tendo uma função muito importante para a construção de valores. Além de desenvolver sua criatividade, interatividade, o homem dá um sentido útil à sua existência. Desta forma, é imprescindível ressaltar que uma socialização cotidiana através do trabalho, possibilite ao homem desenvolver sua capacidade de aprender, tornando-se pessoa mais civilizada e ética.

Assim, pode-se entender que:

[...] Apenas a objetivação real do ser para nós faz com que possam realmente nascer valores. E o fato de que os valores, nos níveis mais altos da sociedade, assumam formas mais espirituais, esse fato não elimina o significado básico dessa gênese ontológica (LUKÁCS apud BARROCO, 2008, p. 27).

Independente da forma de sociedade na qual o homem está inserido, o trabalho sempre será uma lei necessária para sua preexistência e seu desenvolvimento, sempre será ele uma "eterna necessidade natural de mediação do metabolismo entre homem e natureza e, portanto, da vida humana. " (MARX, 1996, p. 172).

Porém o que a história tem mostrado é que o trabalho foi usado como uma forma de dominação do homem com seus semelhantes. Com a evolução das sociedades a escravidão foi se dissipando e dando lugar a outras formas de exploração e dominação, onde o homem tornase cada vez mais alienado pelo capital.

\section{Sentido ontológico do trabalho.}

A palavra ontologia vem do grego ontos "ente" e logoi, "ciência do ser", analisar o trabalho numa perspectiva ontológica é pensar em como ele atua no ser humano, para que ele serve, qual a sua utilidade, num sentido ontológico é o trabalho que dá ao homem um sentido de ser e existir, que torna o homem um ser capaz de recriar o mundo, de desenvolver as suas potencialidades, de destacar-se dos demais, individualizar-se, de transformar a matéria segundo a sua vontade.

O trabalho na ontologia do ser social é: 
[...] um processo de que participam o homem e a natureza, processo em que o ser humano com sua própria ação, impulsiona, regula e controla seu intercâmbio material com a natureza. Defronta-se com a natureza como uma de suas forças. Põe em movimento as forças naturais de seu corpo - braços e pernas, cabeça e mãos -, a fim de apropriar-se dos recursos da natureza, imprimindo-lhes forma útil à vida humana. Atuando assim sobre a natureza externa e modificando-a, ao mesmo tempo modifica sua própria natureza. Desenvolve as potencialidades nela adormecidas e submete ao seu domínio o jogo das forças naturais. Não se trata aqui das formas instintivas, animais, de trabalho. (MARX, 2006, p. 2011).

Portanto, para o homem o trabalho tem (ou deveria ter) um sentido de ser executado, um significado íntimo, deve estar ligado ao seu sentido de ser e existir, através dele o homem constrói a sua história ao criar seus próprios objetos num processo de autoconsciência, em que ele é capaz de fazer as suas próprias escolhas. Ao criar algo através do seu trabalho, este objeto passa a ter um valor significativo, pois segundo Barroco o trabalho passa a expressar "sua capacidade teológica e pratica", o objeto criado pelo homem passa a existir como uma negação ou afirmação das suas capacidades como um ser social.

Nas sociedades capitalistas o objeto feito pelo homem passa a ganhar um novo significado, ele passa a ser apenas um objeto de troca, uma mercadoria. $\mathrm{O}$ trabalho nas sociedades capitalistas ainda está relacionado ao seu meio de sobrevivência, ou seja, ainda é necessário para que a existência humana; para suprir as necessidades do homem, porém perde o seu caráter ontológico e passa a ser alienador, algo que Marx destaca não apenas como uma alienação trabalhista, mas também de vida social em que o trabalho e o consumo são apenas meios de enriquecer os grandes empresários e proprietários.

$\mathrm{Na}$ atual sociedade capitalista, que é uma realidade de muitos países, o capital e o trabalho passam a ter uma relação divergente, Félix (1989, p.37) acentua que " relação social que decorre desse modo de produção é uma relação antagônica em que se confrontam os detentores dos meios de produção e da força de trabalho. ". Tem-se de um lado uma pequena parcela da população que detém o poder e possuem capital, e que necessitam de mão-de-obra para manter e fomentar a riqueza, de outro lado estão os trabalhador que "vendem a sua própria força de trabalho para subsistirem".

Trabalhadores produzem a riqueza, o objeto, o material em troca de um salário que é nada mais do que uma máscara de exploração. A relação de compra e venda entre trabalhador 
Id on Line Revista Multidisciplinar e de Psicologia

Id on Line Multidisciplinary and Psycology Journal

e empregador torna-se uma escolha feita pela necessidade, o trabalhador precisa vender a sua força braçal, a sua inteligência criativa ou artística para suprir as suas necessidades, é um meio de sobrevivência imposta pelo sistema capitalista.

Tonet (2005) afirma que:

[no capitalismo] as necessidades, a cuja satisfação o trabalho se destina imediatamente - por exemplo, comer, vestir, morar, etc. - não são de livre escolha do homem, mas uma imposição exterior a sua natureza mais essencial, de modo que ele tem de satisfazê-las sob pena de perecimento [...] sendo o trabalho um intercâmbio do homem com a natureza, por mais que avance o seu domínio sobre ela, jamais deixará de estar sujeito às leis necessárias que a governam. Haverá, entretanto, diferenças fundamentais entre este reino da necessidade (o trabalho) no capitalismo e no comunismo. No primeiro é o produto que domina o produtor, que estabelece o fim a ser atingido (a reprodução do capital), que lhe impõe as formas concretas do trabalho, as condições gerais e específicas da produção, o tipo de relações entre os homens e a forma de acesso aos bens produzidos. No segundo é o produtor - agora necessariamente sob a forma de "produtores associados" [...] que estabelece os fins [...] e busca as formas mais adequadas para atingi-los. (TONET, 2005, p.141)

O sentido ontológico é perdido no capitalismo, até mesmo a arte que deveria ser uma representatividade de sentimentos e expressões do artista torna-se apenas um produto, a arte nos é conhecida por ser uma atividade emancipadora, mas são poucos os artistas que não a utilizam como uma simples troca e venda no objetivo de possuir mais capital, o homem é reduzido apenas uma máquina de elaborar e criar produtos para vender mais, a inovação e a criatividade passa a ser usada como uma ferramenta para movimentar o mercado, instigar o consumismo e criar novas oportunidades de gerar dinheiro.

\section{Relação entre trabalho e educação}

A sociedade capitalista modificou ontológico do trabalho, e em consequência não somente o trabalho foi a única esfera social que passou a atender as demandas do mercado, a educação por mais que se diga ser uma preparação para a autonomia é na verdade uma preparação para o mercado de trabalho, tão logo a ideia de que o sujeito só é "alguém na vida" se tiver estudado vem desta alienação em que a escola não instiga os alunos a questionarem a 
realidade social, mas a aceita-la e preparar-se para ela, esse "alguém na vida" significa o sujeito que se dedicou toda sua infância e juventude para o estudo na expectativa de que ao tornar-se adulto pudesse ter um bom emprego e ser alguém que possui capital e bens materiais, esse "alguém na vida", não se refere a um cidadão de valores éticos, se refere ao sujeito que está bem empregado e que garante a sua subsistência.

Jimenez, Mendes Segundo e Rabelo em seu artigo sobre educação básica e reprodução do capital destacam que:

\begin{abstract}
A educação tem sido chamada, em última análise, a cumprir o papel basilar, não de construir o homem livre e pleno, mas de ajustar os indivíduos aos ditames do trabalho explorado, que é o motor fundamental da dinâmica do capital. O projeto educacional voltado para a reprodução da ordem vem se efetivando, de um modo geral, através da negação do conhecimento que revela as determinações do real em suas múltiplas dimensões, acoplada à manipulação ideológica das consciências, com vistas à naturalização da exploração e de seus desdobramentos no plano da desumanização crescente do próprio homem. (2008, p. 3)
\end{abstract}

A maior parte da população entende que a educação serve para garantir um emprego, de fato para tornar-se um bom profissional é necessário uma preparação e especialização provinda dos estudos, porém não se pode reduzir a educação as demandas do mercado. O que vem ocorrendo nesses últimos anos é um crescente desemprego entre a classe de pessoas mais escolarizadas, inclusive no Brasil. Segundo uma notícia publicada pelo site do jornal "Correio Brasiliense", em 07 de junho do ano de 2015, entre janeiro e março deste mesmo ano o "total de desempregados com diploma de curso superior" havia aumentado " $21,25 \%$ em relação ao mesmo período de 2014", número apontado pela "Pesquisa Nacional por Amostra de Domicílio (Pnad) Contínua, do Instituto Brasileiro de Geografia e Estatística (IBGE)”.

classe de pessoas também situamos os jovens, são eles os mais atingidos pelo desemprego, mesmo tendo nível superior muitos ou estão desempregados ou estão trabalhando no mercado informal em situação precária, a falta de oportunidade para quem tem nível superior, mas não tem experiência torna-se bem maior.

Existe uma certa alienação de que a educação é a solução para todos os problemas na sociedade. Santos (2012, p. 132) afirma que "a educação, no atual panorama de crise profunda, passa ainda mais a ser defendida como uma tábua de salvação para o buraco que se meteu o capitalismo contemporâneo", porém é uma ilusão acreditar que a educação deve resolver um 
problema que surge da exploração do capital, para Marx a causa dos problemas sociais é a exploração, tem-se atualmente uma crise na educação que é reflexo da crise do trabalho alienado, uma educação que existe para formar profissionais, de ajustar o sujeito para o mercado. A educação está posta na sociedade capitalista como algo importante e essencial para o desenvolvimento da economia, desta forma torna-se uma fantasia idealista pensar em educação como a solução para os problemas sociais, inclusive o desemprego.

\section{Sociedade, trabalho e crise do capitalismo}

É possível afirmar que a sociedade capitalista modificou o sentido do trabalho, o homem deixou de ser o dono do produto para tornar-se escravo dele, as atividades passaram a ser cada vez mais mecânicas e exigir mais esforço e tempo, a cena de Charles Chaplin imitando os movimentos mecânicos na fábrica no filme "Tempos Modernos" é uma representação clara disto, o produto feito pela mão do homem torna-se inalcançável, "a apropriação do objeto aparece como alienação a tal ponto que quanto mais objetos o trabalhador produz tanto menos pode possuir e tanto mais fica dominado pelo seu produto, o capital. " (MARX, 2008).

Parece haver em nossa sociedade uma contradição, o trabalho que deveria ser um meio de realização, de conquistas dos sonhos e metas auxiliando no processo de humanização do ser social acaba sendo uma atividade que nos aprisiona e nos torna indivíduos frustrados, ao invés de libertar o homem o capital acaba por alienar com o conceito de que é feliz quem possui mais, quem pode consumir mais, comprar mais, neste sentido trabalhamos para o consumismo, trabalhamos na ilusão de que a felicidade está no fato de possuir mais coisas, a alienação do consumismo torna-se tão forte a ponto de levar o homem a extrapolar as suas limitações, fazêlo contrair doenças e perder muito tempo, a "viver para trabalhar" e "não trabalhar para viver".

Marx nos diz que:

O trabalhador torna-se uma mercadoria ainda mais barata à medida que cria mais bens. A desvalorização do mundo humano aumenta na razão direta do aumento de valor do mundo dos objetos. O trabalho não cria apenas objetos; ele também se produz a si mesmo e ao trabalhador como uma mercadoria, e, deveras, na mesma proporção em que produz bens. [...] Esse fato simplesmente 

opõe como um ser estranho, como uma força independente do produtor. (MARX, Manuscritos econômico-filosóficos, 2008, grifos do autor).

Há uma crise perceptível em que o trabalhador ganhou valor de "custo de produção", seu valor social não é medido pelo conhecimento, sim pelo capital, formação acadêmica tornouse apenas status, a escolarização não é garantia de emprego e ao mesmo tempo tornou-se um "uma tábua de salvação para o buraco que se meteu o capitalismo contemporâneo" (SANTOS 2012, p. 132) em que o "campo educativo é apontado para o trabalhador como a principal bandeira de superação individual dos problemas estruturais do sistema do capital". O Estado como saída para essa situação oferece cursos profissionalizantes na qual muitos jovens acabam tendo um incentivo maior em fazê-lo do que ingressar no nível superior, pois a educação é tida para eles como uma garantia de trabalho, muitos necessitam ajudar a família ou terem autonomia para ter a sua própria casa, cria-se então uma ideologia social em que vale mais ingressar em cursos para atender a demanda do mercado do que uma universidade, não se vê que a educação tem um papel que vai muito além desse idealismo capitalista, que conhecimento é liberdade, que universidade é uma continuação que leva ao conhecimento cientifico e ao pensamento crítico e consequentemente a libertação da alienação social em que o homem vive atualmente.

\section{Considerações Finais}

A organização social foi possível graças ao trabalho. onde os homens agrupavam-se em comunidades para realizarem atividades em comum, compartilhando também das mesmas necessidades. Com a realização de diversos trabalhos o homem desenvolveu-se como ser social, passou a ser mais conscientes e a diferenciar-se das outras espécies da natureza no sentido que a realização de seu trabalho é uma atividade com um objetivo consciente de suprir as suas necessidades ou realizar um desejo.

Com o advento das maquinas, após a Revolução Industrial, o trabalho passou a ser cada vez mais mecânico, e à medida que a sociedade se tornava capitalista o sentido ontológico do trabalho era esquecido, passando a ser reduzido a uma relação de compra e venda, em que a 
Id on Line Revista Multidisciplinar e de Psicologia

Id on Line Multidisciplinary and Psycology Journal

mão-de-obra é explorada para produzir riqueza. A desigualdade social tornou-se mais evidente e a triste realidade é que o desemprego atinge até mesmo aos que são mais escolarizados.

Percebe-se que na sociedade atual há uma contradição entre trabalho e capital, empregado e empregador, trabalho e escolarização. Todo saber adquirido pelo sujeito, toda experiência e conhecimentos provindo de sua interação social e familiar só ganha valor se for relevante para o mercado, quem reconhece sua valorização é o capital, o sujeito vale aquilo que ele recebe pelo seu trabalho, sua posição hierárquica ou sua instabilidade no emprego.

A sociedade parece viver o seu apogeu, o trabalho e a escolarização só seriam convergentes se houvesse projetos sociais onde o trabalho fosse um direito do cidadão, assim como já acontece com a educação, mesmo que não seja ainda o ideal de escola sonhada pela sociedade .

\section{Referências}

BARROCO, Maria Lucia S. Ética e Serviço Social: fundamentos sócio-históricos. São Paulo: Cortez, 2008.

Maria Lucia Silva. Ética e Serviço social: fundamentos Ontológicos/ Maria Lucia Silva Barroco - 3 ${ }^{\text {a }}$ - ed. - São Paulo, Cortez, 2005.

FÉLIX, Maria de Fátima Costa. Administração escolar: um problema educativo ou empresarial? São Paulo: Cortez: Autores Associados, 1989.

JIMENEZ, Susana; MENDES SEGUNDO, Maria das Dores; RABELO, Jackline. Universalização da educação básica e reprodução do capital: ensaio crítico sobre as diretrizes da política de Educação para Todos. Cadernos de Educação. UFPel. Pelotas- RS. 2008

LESSA, Sergio. O processo de produção/reprodução social: trabalho e sociabilidade. Brasília: CEAD, 1999, p. 20-33.

MARX. Karl O capital. Livro I, v. 1. SP: Editora Nova Cultura, 1996

Karl. O Capital: crítica da economia política. Livro I, Vol. I. $24^{a}$ ed. Trad. Reginaldo Sant'Anna. Rio de Janeiro: Civilização Brasileira, 2006.

11 mar. 2008.

Karl. Manuscritos econômico-filosóficos de 1844. Disponível em: Acesso em: 
Id on Line Revista Multidisciplinar e de Psicologia

Id on Line Multidisciplinary and Psycology Journal

NETTO, José Paulo; BRAZ, Marcelo. Economia Política: uma introdução crítica. São Paulo: Cortez,2006.

SANTOS. Graduação Tecnológica no Brasil: crítica à expansão do ensino superior não universitário. 1. ed. - Curitiba, PR: CRV, 2012.

TONET, I. Educação, cidadania e emancipação humana. Rio Grande do Sul: Ed. Unijuí, 2005. http://www.correiobraziliense.com.br/app/noticia/economia/2015/06/07/internas_economia,4 85744/cresce-o-numero-de-desempregados-com-diploma-de-curso-superior-no-bras.shtml. Acesso em 06 de maio de 2016.

\section{Como citar este artigo (Formato ABNT):}

SAMPAIO, Maria L. C. B. Trabalho: uma abordagem social, ontológica e educacional. Id on Line Revista Multidisciplinar e de Psicologia, Fevereiro de 2017, vol.11, n.34, p. 139-149. ISSN: 1981-1179.

Recebido: 20.02 .2017

Aceito: 27.02 .2017 